\title{
1-D inversion analysis of a shallow landslide triggered by the 2018 Eastern Iburi earthquake in Hokkaido, Japan
}

\author{
Jun Kameda ${ }^{1 *}$ (D) and Atsushi Okamoto ${ }^{2}$
}

\begin{abstract}
Destructive landslides were triggered by the $6.7 M_{w}$ Eastern Iburi earthquake that struck southern Hokkaido, Japan, on 6 September 2018. In this study, we carried out 1-D inversion analysis of one of the shallow landslides near the epicenter using a Bing debris-flow model. At this site, the slope failure comprised cover soil with an initial downslope length of $\sim 80 \mathrm{~m}$ and a thickness of $\sim 7 \mathrm{~m}$ on a slope with $<20^{\circ}$ dip. The landslide moved southeastward with a run-out distance of $\sim 100 \mathrm{~m}$. Inversion analysis of the post-failure deposit geometry was conducted with the Markov Chain Monte Carlo method (MCMC) to optimize the Bingham rheological parameters of the debris. The analysis reproduced several features of the deposit geometry with a yield stress of $\sim 1500 \mathrm{~Pa}$ and dynamic viscosity of $800-$ $3000 \mathrm{~Pa}$ s. The results suggest that the shallow landslide can be approximated by the flow of a viscoplastic fluid with high-mobility debris and a maximum frontal velocity of $6-9 \mathrm{~m} / \mathrm{s}$, with a flow duration of 2-4 min.
\end{abstract}

Keywords: 2018 Hokkaido Eastern Iburi earthquake, Shallow landslide, Inversion analysis

\section{Introduction}

The Eastern Iburi earthquake $\left(M_{\mathrm{w}}=6.7\right)$ occurred in southern Hokkaido, Japan, on 6 September 2018 (Fig. 1a). The resulting strong ground motion had a maximum intensity of 7 on the Japan Meteorology Agency (JMA) intensity scale and caused shallow landslides as well as a few large-scale deep-seated landslides near the epicenter (Yamagishi and Yamazaki 2018; Osanai et al. 2019). Most of the shallow landslides show long runouts of debris on relatively gentle slopes $\left(<30^{\circ}\right.$; Kasai and Yamada 2019; Osanai et al. 2019) and are classified as earthflows or earth slides according to the scheme of Varnes (1978). The widespread hills in southern Hokkaido are covered by volcanic soils derived from material produced by several nearby volcanos. The soils are thought to have been weakened by heavy rainfall from a typhoon that passed

\footnotetext{
*Correspondence: kameda@sci.hokudai.ac.jp

${ }^{1}$ Department of Earth and Planetary Sciences, Faculty of Science,

Hokkaido University, N10W8, Kita-ku, Sapporo 060-0810, Japan

Full list of author information is available at the end of the article
}

through the area the day before the earthquake (Osanai et al. 2019).

Field observations of the shallow landslides revealed that the volcanic soil close to the slip zone is clay-rich and contains the clay mineral halloysite (Chigira et al. 2019; Kameda et al. 2019). Halloysite is a typical alteration product of volcanic glass (Wada 1977) and is commonly observed on the slip surfaces of other landslide sites in volcanic areas of Japan (Chigira and Yokoyama 2005; Chigira et al. 2012). The field survey also found evidence of liquefaction of volcanic soil (Kameda et al. 2019). Geotechnical experiments using a triaxial apparatus have demonstrated that the volcanic soils around the slip zone have a low shear resistance and are more susceptible to liquefaction than are other layers ( $\mathrm{Li}$ and Wang 2020). The earthquake possibly caused liquefaction and fluidization of the water-saturated soils, resulting in multiple shallow landslides in this area.

In addition to the works mentioned above, other studies have analyzed the landslides by field surveys, laboratory experiments, and image analysis (e.g., Kawamura 

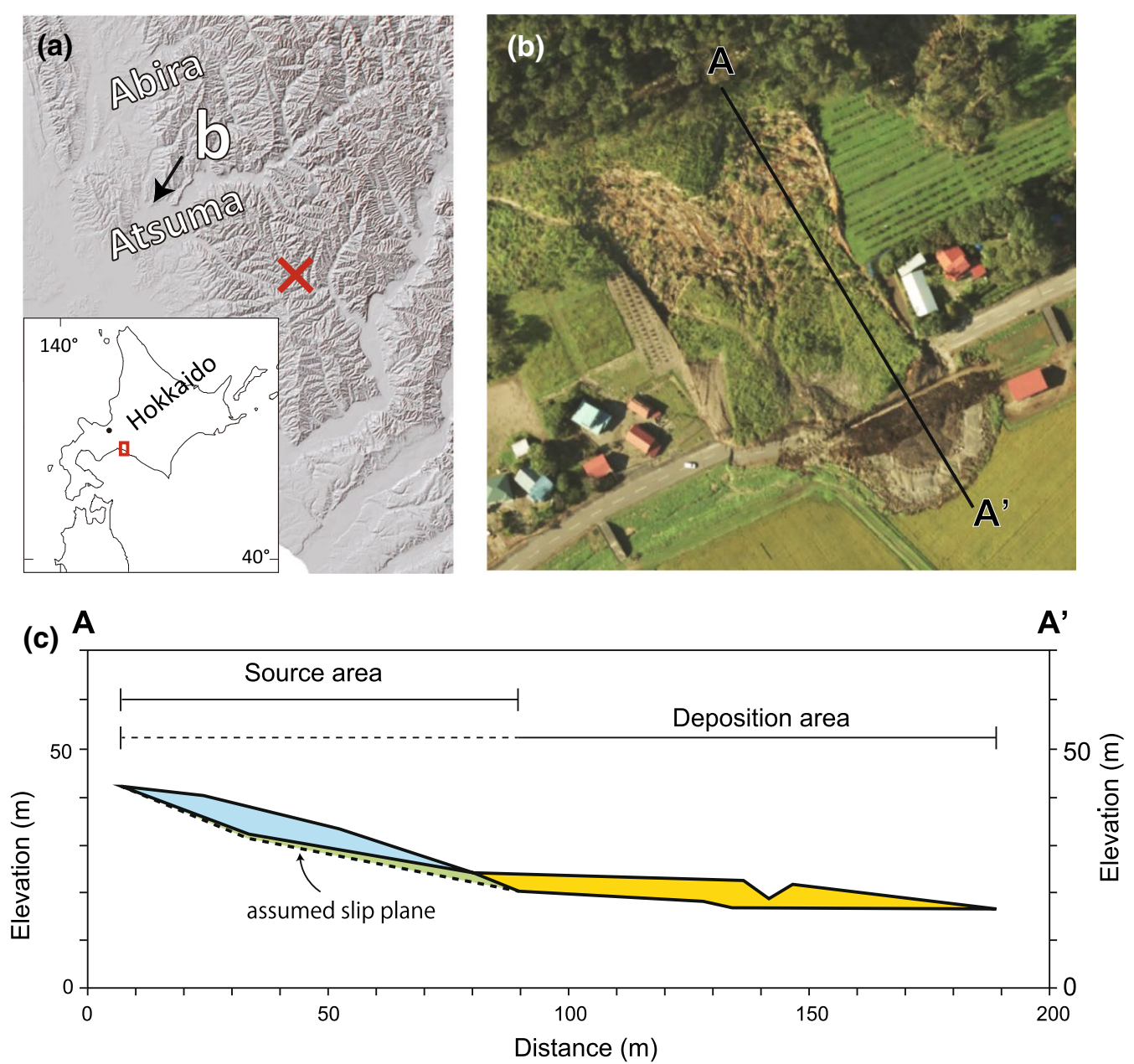

Fig. 1 a Location of the epicenter of the Eastern Iburi earthquake (red cross) and the studied landslide in the Asahi district ( $42^{\circ} 44^{\prime} 10.6^{\prime \prime} \mathrm{N}$, $141^{\circ} 52^{\prime} 39.8^{\prime \prime}$ E; black arrow). b Aerial view of the landslide (taken by the Geospatial Information Authority of Japan 2018). c Cross-section of the landslide based on the field survey by Li and Wang (2020). Soils before and after the failure are marked by light blue and green, and yellow and green, respectively

et al. 2019; Wang et al. 2019; Zhang, et al. 2019; Ito et al. 2020), and they reported on the geological history and triggering mechanisms. To complement these studies, we conducted numerical modeling of the landslide and discuss its post-failure behavior. We selected one of the shallow landslides for our study, whose geometry was investigated in a previous field survey (Li and Wang 2020). We employ a Bing debris-flow model (Imran et al. 2001) for inversion analysis of the landslide geometry and discuss the rheological properties of the collapse debris to interpret its post-failure flow behavior.

\section{Landslide}

The studied landslide is located in the Asahi district of the Atsuma town in Hokkaido $\left(42^{\circ} 44^{\prime} 10.6^{\prime \prime} \mathrm{N}\right.$, $141^{\circ} 52^{\prime} 39.8^{\prime \prime}$ E; Fig. 1a). The volcanic soil slid southeastward on a slope that dips $19^{\circ}$ at its highest point and decreases in dip down-slope. The run-out distance of the landslide is $\sim 100 \mathrm{~m}$ (Fig. 1b, c; Li and Wang 2020). This landslide was selected for numerical analysis because of its simple geometry. Figure 1c shows a cross-section through the slope. Due to poor field exposure, we assume the depth of the slip plane on the slope based on the thickness of the post-failure debris, with the depth increasing down-slope. Despite making this assumption, our model successfully reproduces the whole geometry of the deposit including the slope.

\section{Methods}

\section{Forward modeling}

We used a Bing debris-flow model (Imran et al. 2001) to conduct a numerical analysis of the landslide. This model assumes two layers of debris (i.e., an upper plug-layer and a lower shear-layer) that flow laminarly with rheological 
soil properties described by a viscoplastic HerschelBulkley model:

$$
\left|\frac{\gamma}{\gamma_{\mathrm{r}}}\right|^{n}=\left\{\begin{array}{l}
0 \quad \text { if }|\tau|<\tau_{\mathrm{y}} \\
\frac{\tau}{\tau_{\mathrm{y}} \operatorname{sgn}(\gamma)}-1 \quad \text { if }|\tau| \geq \tau_{\mathrm{y}}
\end{array}\right.
$$

where $\tau$ is the shear stress, $\tau_{\mathrm{y}}$ is the yield stress, and $\gamma$ is the strain rate. A reference strain rate, denoted by $\gamma_{\mathrm{r}}$, is defined as follows:

$$
\gamma_{\mathrm{r}}=\left(\frac{\tau_{\mathrm{y}}}{\mu}\right)^{\frac{1}{n}}
$$

where $\mu$ is the dynamic viscosity. The volcanic soil of the studied landslide is assumed to behave as a Bingham fluid, which is a limiting case for the Herschel-Bulkley model with $n=1$. The Bingham model is the most commonly used viscoplastic model that describes the behavior of debris or mud flows (Jiang and LeBlond 1993; Wan and Wang 1994; Julien 1995; Naruse 2016). The integral equations of the debris flow on a Lagrangian framework are described by the following three conservation equations for mass and momentum (Jiang and LeBlond 1993; Huang and Garcia 1998; Pratson et al. 2001; Imran et al. 2001; Naruse 2016):

$$
\begin{aligned}
& \frac{\partial D}{\partial t}+\frac{\partial}{\partial x}\left[U_{\mathrm{P}}\left(D_{\mathrm{P}}+\frac{2}{3} D_{\mathrm{S}}\right)\right]=0, \\
& \frac{\partial}{\partial t}\left(U_{\mathrm{P}} D_{\mathrm{P}}\right)+U_{\mathrm{P}} \frac{\partial D_{\mathrm{S}}}{\partial t}+\frac{\partial}{\partial x}\left(U_{\mathrm{P}}^{2} D_{\mathrm{P}}\right)+\frac{2}{3} U_{\mathrm{P}} \frac{\partial}{\partial x} U_{\mathrm{P}} D_{\mathrm{S}}=-g D_{\mathrm{P}}\left[1-\frac{\rho}{\rho_{\mathrm{m}}}\right] \frac{\partial D}{\partial x}+g D_{\mathrm{P}}\left[1-\frac{\rho}{\rho_{\mathrm{m}}}\right] S-\frac{\mu}{\rho_{\mathrm{m}}}, \\
& \frac{2}{3} \frac{\partial}{\partial t}\left(U_{\mathrm{P}} D_{\mathrm{S}}\right)-U_{\mathrm{P}} \frac{\partial D_{\mathrm{S}}}{\partial t}+\frac{8}{15} \frac{\partial}{\partial x}\left(U_{\mathrm{P}}^{2} D_{\mathrm{S}}\right)-\frac{2}{3} U_{\mathrm{P}} \frac{\partial}{\partial x} U_{\mathrm{P}} D_{\mathrm{S}}=-g D_{\mathrm{S}}\left[1-\frac{\rho}{\rho_{\mathrm{m}}}\right] \frac{\partial D}{\partial x}+g D_{\mathrm{S}}\left[1-\frac{\rho}{\rho_{\mathrm{m}}}\right] S-2 \frac{\mu}{\rho_{\mathrm{m}}} \frac{U_{\mathrm{P}}}{D_{\mathrm{S}}},
\end{aligned}
$$

the lower layer. Therefore, we assume $\rho_{\mathrm{m}}=1300 \mathrm{~kg} / \mathrm{m}^{3}$ in our model.

We developed a MATLAB code to numerically solve Eqs. (3)-(5). The equations were assembled in a staggered lattice using a finite difference method with a deformable moving grid system. Following Imran et al. (2001), a numerical viscosity of 0.001 was used to prevent the solution from becoming unstable. More detailed information on the solution procedure can be found in Imran et al. (2001). The calculation was stopped when the frontal velocity of the debris flow decreased to $1 \mathrm{~cm} / \mathrm{s}$.

\section{Inversion analysis}

Based on the geometry of the landslide deposit, inversion analysis was conducted to optimize the parameters $\tau_{\mathrm{y}}$ and $\gamma_{\mathrm{r}}$ in Eq. (2). Since our analysis is 1-D, lateral flow is ignored. However, the volume of debris before and after failure is not equal along the constructed cross-section (Fig. 1c), with the latter being larger than the former by $17 \%$. This implies that soils from outside the survey line contributed to the final geometry of the deposit. For this reason, we use a volume of the post-failure deposit that is artificially reduced (shortened vertically), so that it is identical to the pre-failure volume. Due to these limitations, we aim at reproducing key features of the debris where $U_{\mathrm{P}}$ is the plug-layer velocity, $D_{\mathrm{P}}, D_{\mathrm{S}}$, and $D$ are the plug-layer, shear-layer, and total thickness of the debris, respectively, $S$ is the slope angle, $t$ is time, $x$ is the position along the slope (downward is positive), $g$ is gravitational acceleration, $\rho$ is the density of air, and $\rho_{\mathrm{m}}$ is the density of the debris material. According to Li and Wang (2020), the clay-rich volcanic soil near the base of the landslide (known as Ta-d pumice MS) has a specific gravity of $2.631\left(\rho_{\mathrm{m}}=1177 \mathrm{~kg} / \mathrm{m}^{3}\right)$ and a water content of $206 \%$ at a degree of saturation $\left(S_{\mathrm{r}}\right)$ of $92.8 \%$. The upper volcanic soil (Ta-d pumice with volcanic ash) has a specific gravity of $2.553\left(\rho_{\mathrm{m}}=1122 \mathrm{~kg} / \mathrm{m}^{3}\right)$ and a water content of $121 \%$ at a degree of saturation $\left(S_{\mathrm{r}}\right)$ of $76.2 \%$. If these soils were fully saturated at failure (i.e., $S_{\mathrm{r}}=100 \%$ ), $\rho_{\mathrm{m}}$ is estimated to be $1240 \mathrm{~kg} / \mathrm{m}^{3}$ for the upper layer and $1310 \mathrm{~kg} / \mathrm{m}^{3}$ for
In the inversion analysis, we defined an objective function as a residual sum of squares between the observed (corrected) and modeled deposit thickness

$$
F=\sum_{i=1}^{n}\left(D_{\mathrm{o} i}-D_{i}\right)^{2}
$$

where $n$ is the number of grid points and $D_{\mathrm{o} i}$ is the observed thickness of the deposit at $i$ grid point. Based on the result of the forward model, the thickness of the modeled deposit at each grid point $\left(D_{i}\right)$ was calculated using the one-dimensional data interpolation method. The analysis was done over the length of the deposit, from $x=76.5$ to $184.68 \mathrm{~m}$, which consisted of 58 grid points. The source area was excluded from the inversion analysis 
( $x=0$ to $76.5 \mathrm{~m}$ ), because we assumed the thickness of the deposit on this area as described above.

Since the $F$ function is non-linearly dependent on the fitting parameters, a Markov Chain Monte Carlo (MCMC) method was applied to optimize the fitting parameters over a range of values. Details of this method are outlined by Metropolis et al. (1953). For an MCMC simulation, a candidate value for one of the unknown parameters is tested by adding a random number $\left(n_{\mathrm{r}}=[-1,1]\right)$ to the old candidate, namely $\log _{10}\left(P_{i, \text { can }}\right)=\log _{10}\left(P_{i}\right)+n_{\mathrm{r}}$, where $P_{i}$ and $P_{i, \text { can }}$ are the old and current candidates, respectively. Therefore, the candidate parameter vector for one local step can be described as $\varphi_{\text {can }}=\left\{P_{1, \text { can }}, P_{2}, \ldots, P_{N}\right\} . F\left(\varphi_{\text {can }}\right)$ is then calculated from these parameters and $\Delta F$ is evaluated from $\Delta F=F(\varphi)-F\left(\varphi_{\text {can }}\right)$.

The candidate vector $\varphi_{\text {can }}$ is accepted if the probability is $\min \left(1, \exp \left(-\Delta F \beta_{N}\right)\right)$, where $\beta_{N}$ is the "inverse temperature", which controls the acceptance or rejection of the candidate values. At low $\beta_{N}$, the candidate value is updated when $-\Delta F>0$. At high $\beta_{N}$, this is not the case. The appropriate $\beta_{N}$ is problem-dependent, and in this work, $\beta_{N}$ was set to $0.5-1.0$ by trial-and-error $\left(\beta_{\mathrm{N}}\right.$ was fixed during one series of calculations). After one local update, the next unknown parameter is tested in a similar way. One Monte Carlo Step (MCS) is defined as N trials (i.e., the number of unknown parameters examined) of the local update, and $E_{\text {sum }}$ is obtained by the arithmetic sum of $F$ of each MCS. Schematic flowchart of the MCMC method for our inversion analysis is shown in Fig. 2.

\section{Results}

The results of MCMC inversion are shown on a yield stress-viscosity $\left(\tau_{\mathrm{y}}-\mu\right)$ plot (Fig. 3). The parameters in the simulation are treated in logarithmic form $\left(\log _{10}\left(\tau_{\mathrm{y}}\right)\right.$ and $\left.\log _{10}\left(\gamma_{\mathrm{r}}\right)\right)$, but to clearly illustrate the results, $E_{\text {sum }}$ values are plotted against $\tau_{\mathrm{y}}$ and $\mu$. We used several initial value conditions indicated by the red crosses in Fig. 3 . However, after several MCSs, the resulting viscosity and yield stress values converged to two distinct domains: a high-viscosity domain and a low-viscosity domain. $E_{\text {sum }}$ values for these domains are similar, ranging from $\sim 17$ to 20 , which corresponds to an $F$ value of $\sim 9$ to 10 and a trial number $N=2$.

Figure 4 shows how $\tau_{\mathrm{y}}$ and $\mu$ are updated with the progress of the MCMC simulation after a converged state is achieved. In a converged state, the accepted yield stress values vary steadily between 1450 and $1800 \mathrm{~Pa}$, while the viscosity values fluctuate between two distinct ranges of values: $1000 \mathrm{~Pa} \mathrm{~s}$ and 1500-3000 Pa s (Fig. 4). Of the $>8000$ MCSs, the $\sim 6200$ MCSs yield viscosity values in

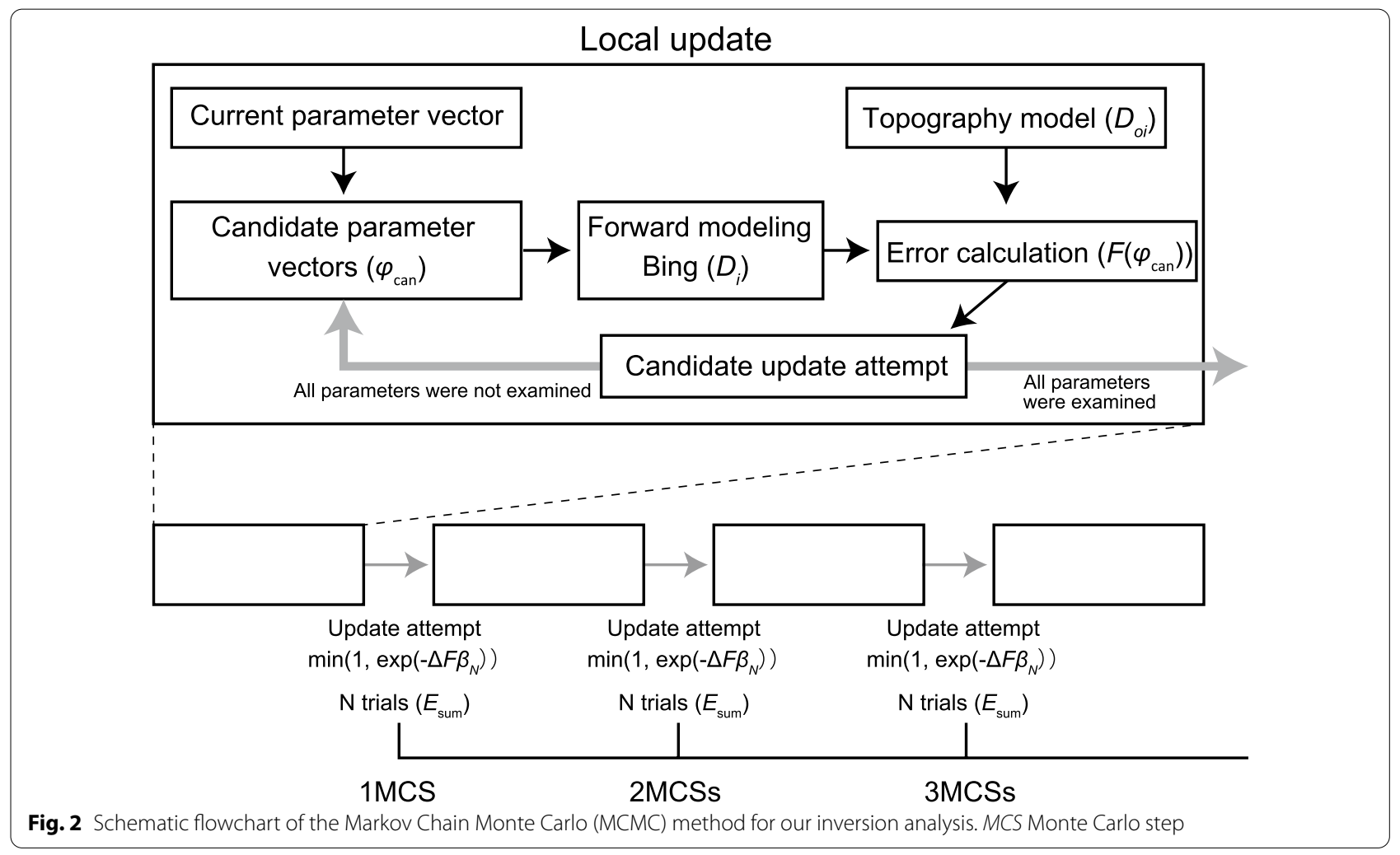




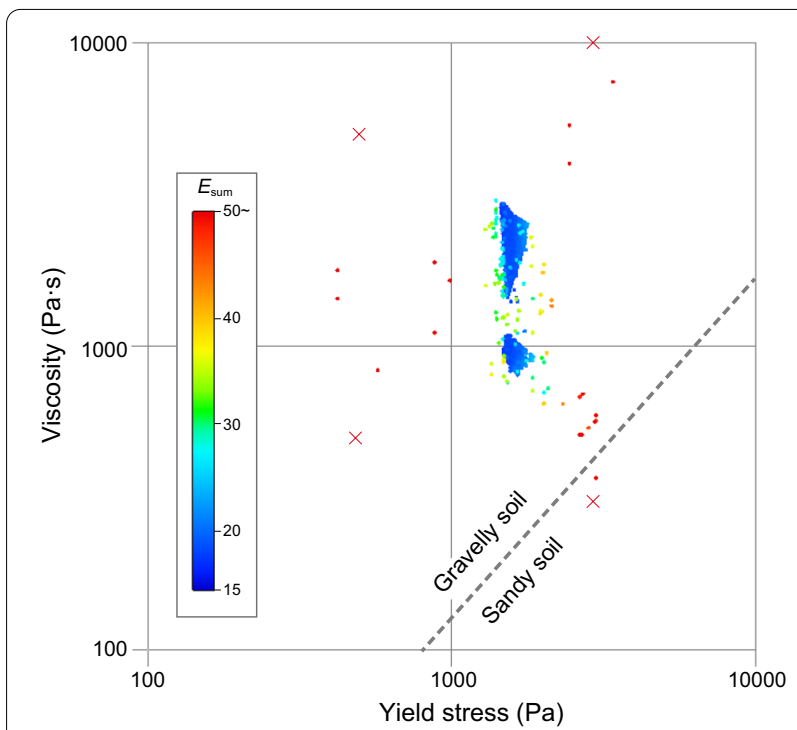

Fig. 3 Yield stress-viscosity diagram showing the results of the MCMC simulation. Initial values are shown by red crosses. Resulting values are plotted with their corresponding $E_{\text {sum }}$ value indicated by the color scale. The inferred boundary between gravel-rich and sand-rich soils (grey dash line) is from Jeong et al. (2010)

the high-viscosity domain, while the remaining $\sim 2300$ MCSs yields viscosity values in the low-viscosity domain. Based on these results, the probability distributions of $\log _{10}\left(\tau_{\mathrm{y}}\right)$ and $\log _{10}\left(\gamma_{\mathrm{r}}\right)$ values in the two domains are individually estimated (Fig. 5). The mean and standard deviation of $\log _{10}\left(\tau_{\mathrm{y}}\right)$ and $\log _{10}\left(\gamma_{\mathrm{r}}\right)$ in the high-viscosity domain are $3.192(1 \sigma=0.0169)$ and $-0.151(1 \sigma=0.0772)$, respectively, corresponding to a yield stress of $1554 \mathrm{~Pa}$ and viscosity of 2200 Pa s (Fig. 5a, b). The mean and standard deviation of $\log _{10}\left(\tau_{\mathrm{y}}\right)$ in the low-viscosity domain are comparable to the values in the high-viscosity domain at $3.201(1 \sigma=0.0166)$, which gives a similar yield stress of $1588 \mathrm{~Pa}$ (Fig. 5c). However, $\log _{10}\left(\gamma_{\mathrm{r}}\right)$ in the low-viscosity domain has a larger mean value of 0.225 and lower standard deviation $(1 \sigma=0.0347)$ than that in the high-viscosity domain and, consequently, a lower viscosity of $945 \mathrm{~Pa} \mathrm{~s}$ (Fig. 5d).

Figure 6 shows the results of the forward modeling based on the two optimized parameter sets obtained from the MCMC simulation. The deposit thickness and frontal velocity are plotted against the distance from the top of the source area for both the high-viscosity and low-viscosity parameter sets. In the case of the high-viscosity parameter set (Fig. 6a), the debris flow accelerates to $6.5 \mathrm{~m} / \mathrm{s}$ before quickly decelerating to $1 \mathrm{~m} / \mathrm{s}$. It then continues to flow with a velocity of $<1 \mathrm{~m} / \mathrm{s}$ until it stops moving, $252 \mathrm{~s}$ after initial failure, at a distance of $175 \mathrm{~m}(F=9.185)$. In the lowviscosity case (Fig. 6b), the debris flow accelerates to a frontal velocity of $9 \mathrm{~m} / \mathrm{s}$ and keeps this high-velocity state for a certain period. The debris flow then quickly decelerates and stops flowing after $115 \mathrm{~s}(F=9.033)$. Although the low-viscosity debris flow is completed in a shorter timeframe than the high-viscosity debris flow, the final deposit profiles are similar in both cases.

\section{Discussion and conclusions}

Our 1-D inversion analysis yields rheological parameters that closely reproduce the observed deposit profile (Fig. 6). The parameters are separated into two domains that both lie outside the field of sand-rich soils as
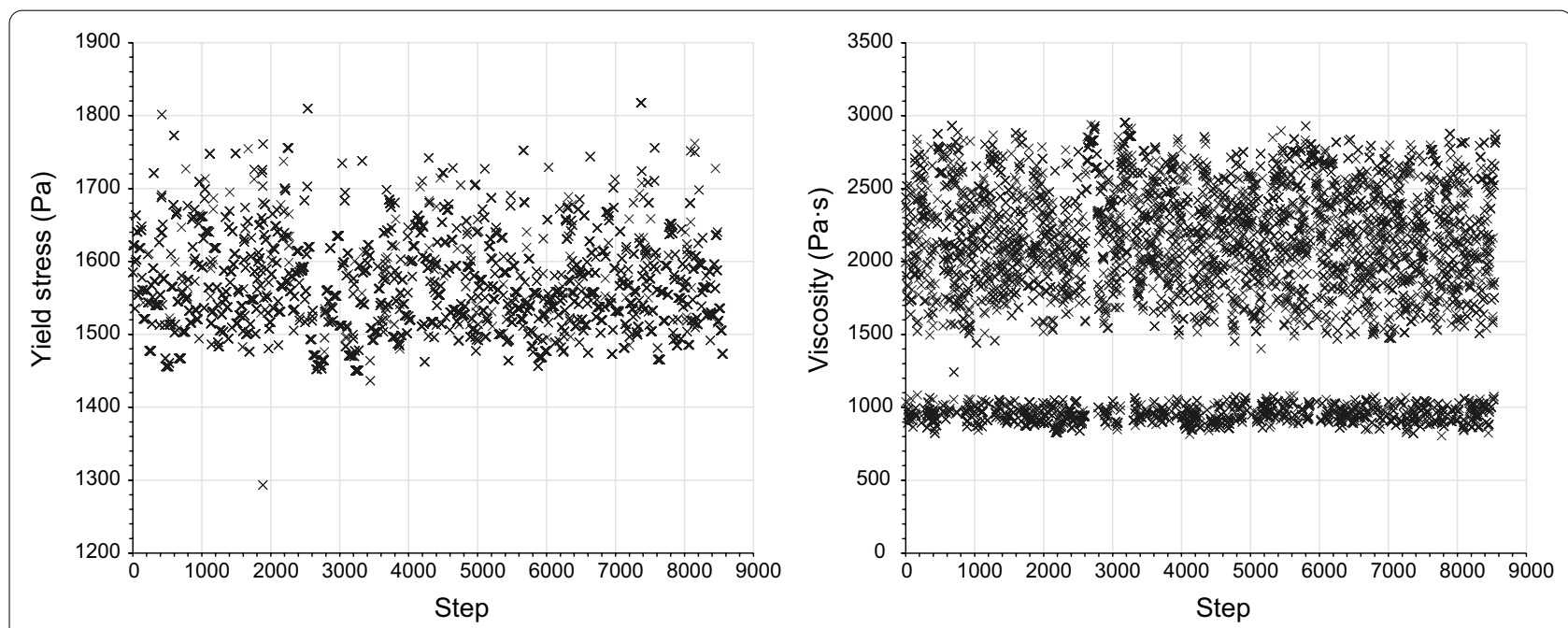

Fig. 4 Behavior of yield stress and viscosity over 8500 MCSs. Left: fitting parameter $\log _{10}\left(\tau_{y}\right)$ recalculated as $\tau_{y}$. Right: fitting parameter $\log _{10}\left(\gamma_{\mathrm{r}}\right)$ recalculated as $\mu$ 

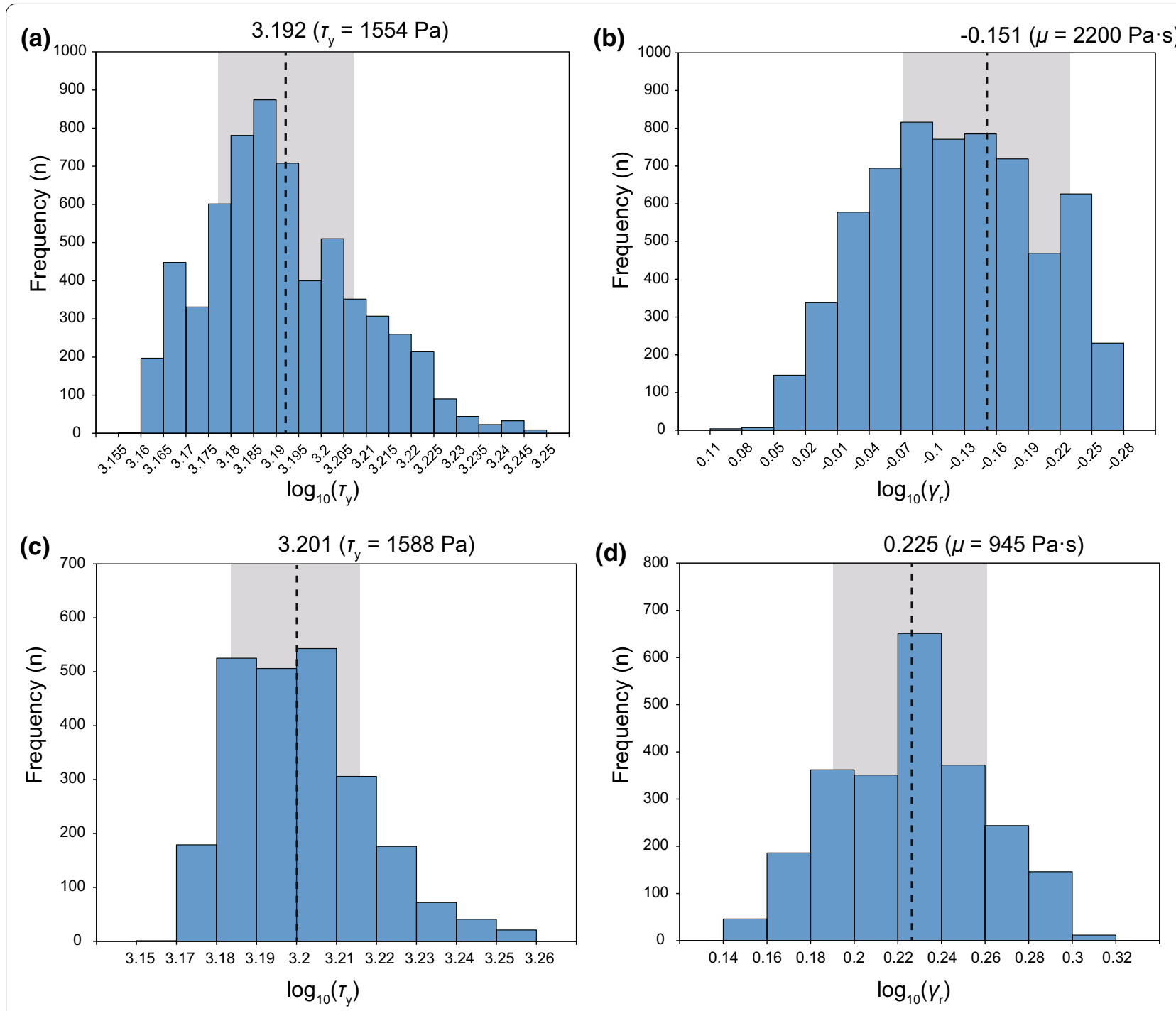

Fig. 5 Probability distributions of $\log _{10}\left(\tau_{y}\right)$ and $\log _{10}\left(\gamma_{r}\right)$ obtained by the MCMC simulation. Mean values (dashed line) and standard deviations (grey shading) are shown for the high-viscosity $(\mathbf{a}, \mathbf{b})$ and low-viscosity $(\mathbf{c}, \mathbf{d})$ domains

classified by Jeong et al. (2010) (Fig. 3). The boundaries between the fields of sandy and silty soils, and between silty and clay-rich soils occur at lower viscosities than those obtained for the studied landslide (Locat 1997; Jeong et al. 2010). Although this suggests that the rheology of the volcanic soil is more comparable to that of a gravel-rich soil, care should be taken in making this comparison. The basal volcanic soil of a similar landslide (Ta-d) triggered by the same earthquake contains the clay mineral halloysite (Kameda et al. 2019), and suspensions of halloysite generally exhibit shear-ratedependent resistance as assumed in this study (Theng and Wells 1995), but the rheological properties of halloysite-bearing soils are poorly defined. Moreover, the parameters obtained in this study likely represent the bulk rheological properties of the collapsed soil rather than of the sorted fine-grained materials that are generally used in laboratory experiments (Locat 1997; Jeong et al. 2010). On the other hand, several studies have reported the rheological properties of soils involved in flow-like landslides based on numerical modeling (Malet et al. 2004; Carrière et al. 2018). Using a Bing model, Carrière et al. (2018) conducted back analyses of several flow-like landslides in Pont-Bourquin, Switzerland, that have a geometry (maximum thickness of $3 \mathrm{~m}$, length of $100 \mathrm{~m}$, run-out distance of $130-160 \mathrm{~m}$ ) similar to that of the present study. They reported possible yield stresses of 550-1300 Pa. Their results are 


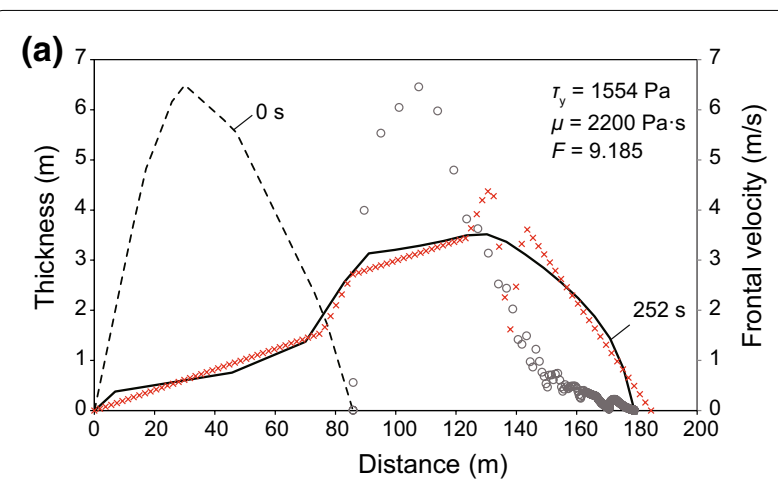

(b)

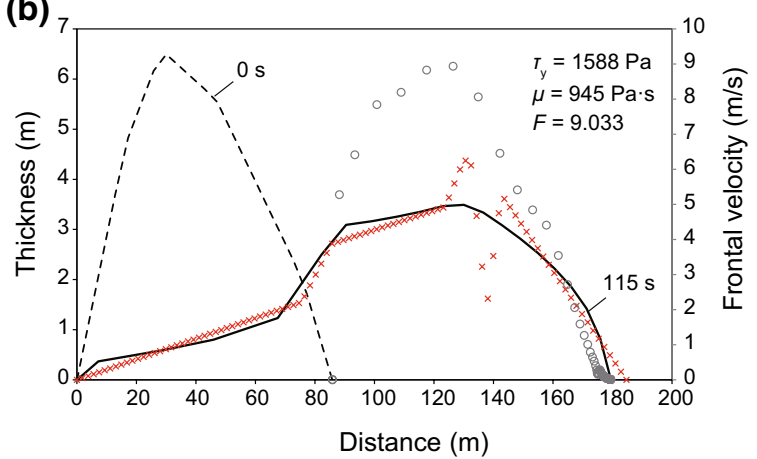

Fig. 6 Results of forward modeling of the debris flow with optimized viscosity and yield stress parameters. The thickness of the deposit is plotted against distance from the top of the source area. a Results of the high-viscosity debris flow with $\tau_{y}=1554 \mathrm{~Pa}$ and $\mu=2200 \mathrm{~Pa}$ s. b Results of the low-viscosity debris flow with $\tau_{\mathrm{y}}=1588 \mathrm{~Pa}$ and $\mu=945$ Pa s. Black dashed line: initial deposit profile; black line: final modeled deposit profile; red crosses: observed deposit profile; grey circles: frontal velocity of the debris flow $(\mathrm{m} / \mathrm{s})$

not directly comparable to our study, since they used the Herschel-Bulkley model with $n=\sim 0.3$ and the debris is composed mainly of quartz and mica (Carrière et al. 2018), which are absent in the volcanic soil of the Atsuma region (Kameda et al. 2019). Nevertheless, the obtained yield stress is in the same order of magnitude as our results. Further experiments are necessary to test the validity of our results and assess which viscosity value gives the best fit to the flow of the volcanic soil.

Although the observed deposit profile is closely reproduced by our numerical model, there are some minor differences. For instance, the observed debris profile shows $\sim 1 \mathrm{~m}$ of uplift at a distance of $130 \mathrm{~m}$ (Figs. 1 and 6). In our numerical model, this is observed as a transient phenomenon that gradually disappears with the progression of the debris flow. Figure 7 shows time snapshots of the debris profile to show temporal changes in the morphology of the debris flow in the high-viscosity case. During the first 2 min (Fig. 7a, b), uplift of the debris occurs at a distance of $130 \mathrm{~m}$, which resembles the uplift feature in the observed debris profile (Fig. 6). During the period after $2 \mathrm{~min}$, the uplift at $130 \mathrm{~m}$ ceases to occur (Fig. 7c, d). At $130 \mathrm{~m}$ from the top of the source area, the slide slope is steeper $\left(14^{\circ}\right.$ dip) over a distance of $\sim 5 \mathrm{~m}$ (Fig. 1c). This area corresponds to the sloping ground between the road and the field, which might explain the transient uplift (i.e., a stack of debris behind the slope). The conservation of this feature in the debris-flow deposit may be a result of the local variation in rheological soil properties and/or water saturation state. Such variation could arise from a vertical layering of different volcaniclastic strata, which is not incorporated in our model.

Another discrepancy between our modeled profile and the observed profile is the $\mathrm{V}$-shaped depression directly behind the uplift at 130-145 m (Fig. 6). One explanation for this depression is a lateral crack in the debris deposit. To discuss such features, it would be necessary to use numerical modeling techniques that are capable of reproducing flow processes in discontinuous media (e.g., the discrete element method). However, another interpretation is a local erosion of a small drainage channel located south of the road. In fact, it seems there is a small impoundment on the right and it is possible to see a little stream on the left (Fig. 1b). If the latter interpretation is correct, then our model seems to reproduce the observed deposit profile quite well, including the microtopographic features.

In recent years, 3D simulations of landslides considering various rheological models have been conducted (Kelfoun and Druitt 2005; Pirulli and Mangeney 2008), but in most of these studies, the model parameters are calibrated by trial-and-error. In addition, seismic signals associated with landslides rather than deposit profiles are often used in inversions analysis of landslides (Yamada et al. 2018; Moretti et al. 2020). Although there are still some uncertainties in our analysis, the model successfully fits the observed deposit profile with reasonable yield stress and viscosity values, and therefore, the MCMC-based inversion analysis presented here is useful as a new methodology for reproducing landslide processes and inferring material properties. The results of our analysis suggest that the shallow landslide can be approximated by the flow of a viscoplastic fluid over a period of several minutes. The morphological features, geological background, and rheological properties of the landslide are similar to those of other shallow landslides triggered by the 2018 earthquake (Osanai et al. 2019; Li and Wang 2020). The many slope failures in the region might therefore have collapsed in a similar manner to that outlined in the present study. 


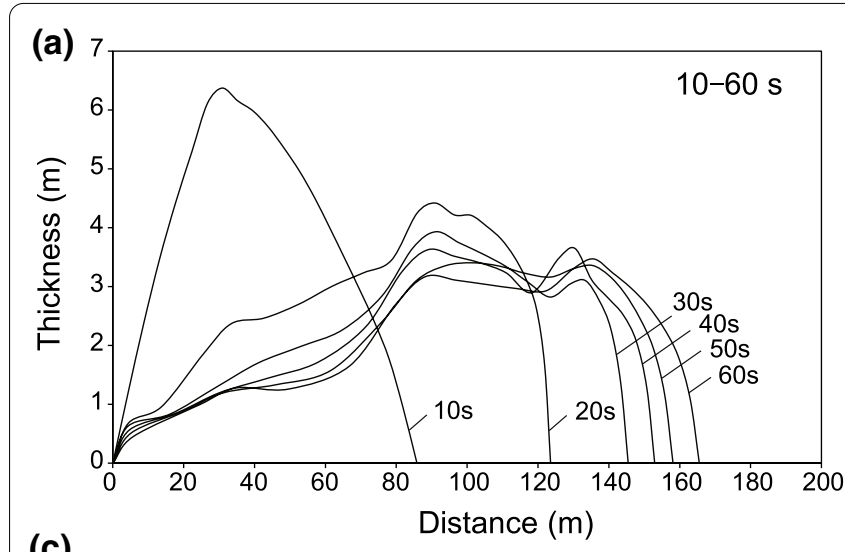

(c)

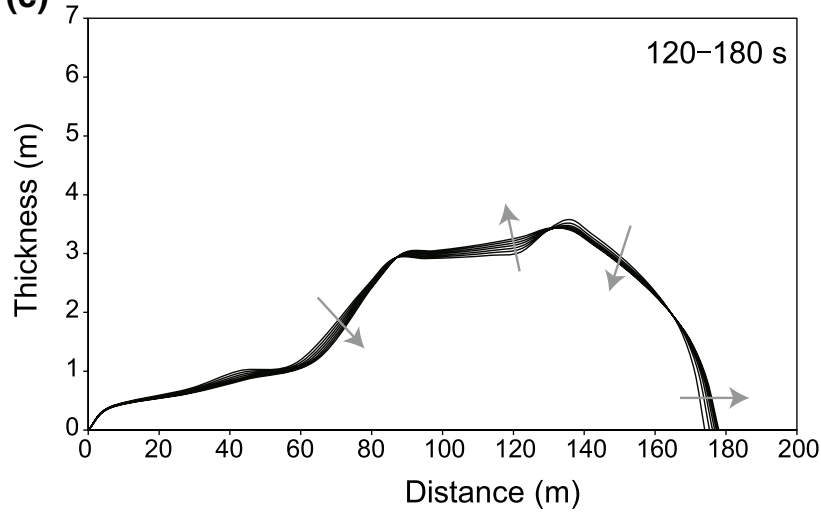

(b) 7

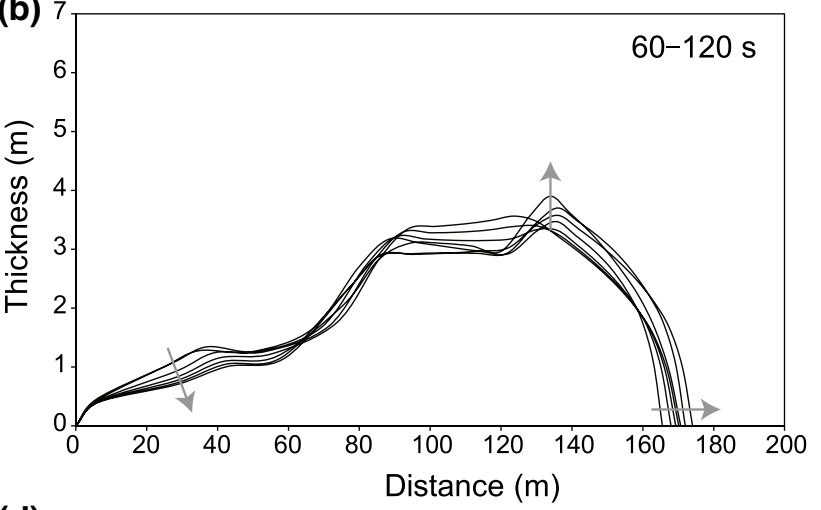

(d)

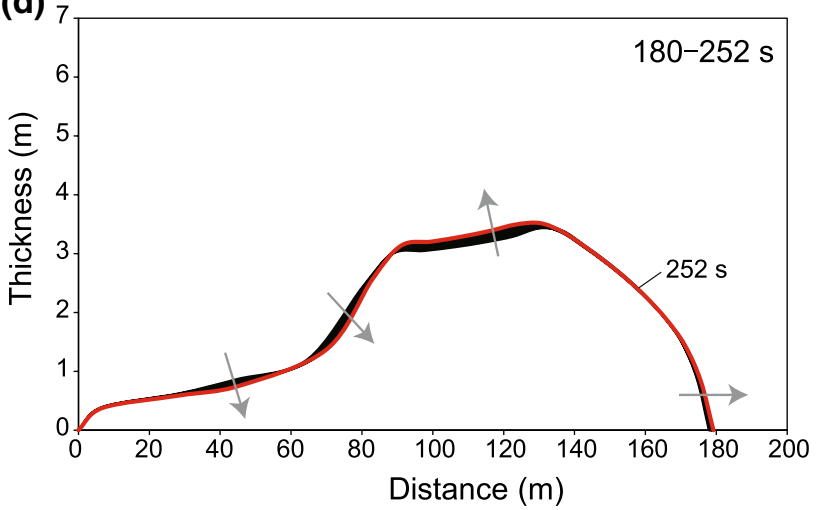

Fig. 7 Profiles of the modeled debris flow during the intervals from a 10 to $60 \mathrm{~s}, \mathbf{b} 60$ to $120 \mathrm{~s}, \mathbf{c} 120$ to $180 \mathrm{~s}$, and d 180 to $252 \mathrm{~s}$. The profiles were calculated using the optimized high-viscosity parameter set ( $\tau_{y}=1554 \mathrm{~Pa}, \mu=2200 \mathrm{~Pa}$ s). Grey arrows indicate the movement direction of the debris surface with time. The final deposit geometry is indicated by the red profile in $\mathbf{d}$

\section{Acknowledgements}

We acknowledge Giulia Bossi, two anonymous reviewers, handling editor Tadashi Yamasaki, and editor Takeshi Sagiya for their constructive comments, which greatly improved the manuscript.

\section{Authors' contributions}

$\mathrm{JK}$ and $\mathrm{AO}$ designed the study, JK carried out the forward modeling, and JK and $\mathrm{AO}$ carried out inversion analysis and constructed the manuscript. Both authors read and approved the final manuscript.

\section{Funding}

This work was supported by a JSPS Grant-in-Aid for Scientific Research (18H0129508).

\section{Availability of data and materials}

Data are available on request by contacting JK.

\section{Declarations}

\section{Competing interests}

The authors declare that they have no competing interests.

\section{Author details}

${ }^{1}$ Department of Earth and Planetary Sciences, Faculty of Science, Hokkaido University, N10W8, Kita-ku, Sapporo 060-0810, Japan. ${ }^{2}$ Graduate School of Environmental Studies, Tohoku University, Sendai, Japan.

Received: 4 March 2021 Accepted: 18 May 2021

Published online: 26 May 2021

\section{References}

Carrière SR, Jongmans D, Chambon G, Bièvre G, Lanson B, Bertello L, Berti M, Jaboyedoff M, Malet JP, Chambers JE (2018) Rheological properties of clayey soils originating from flow-like landslides. Landslides 15:16151630. https://doi.org/10.1007/s10346-018-0972-6

Chigira M, Yokoyama O (2005) Weathering profile of non-welded ignimbrite and the water infiltration behavior within it in relation to the generation of shallow landslides. Eng Geol 78:187-207

Chigira M, Nakasuji A, Fujiwara S, Sakagami M (2012) Catastrophic landslides of pyroclastics induced by the 2011 off the Pacific Coast of Tohoku Earthquake. In: Earthquake-induced landslides, Proc. Int. Symp, Kiryu, Japan. Springer, Berlin, pp 139-147

Chigira M, Tajika J, Ishimaru S (2019) Landslides of pyroclastic fall deposits induced by the 2018 Eastern Iburi earthquake with special reference to the weathering of pyroclastics. DPRI Annu 62:348-356

Geospatial Information Authority of Japan (2018) https://maps.gsi.go.jp/\# 12/42.770442/141.985660/\&base=std\&ls=std\%7C20180906hokka ido_atsuma_0906do\%7Cexperimental_anno\&blend $=0 \& d i s p=111 \&$ $\mathrm{Icd}=20180906$ hokkaido_atsuma_0906do\&vs=c1j0h0k0l0u0t0zOr0s0 $\mathrm{mof} 1 \& \mathrm{~d}=\mathrm{vl}$

Huang X, Garcia MH (1998) A Herschel-Bulkley model for mud flow down a slope. J Fluid Mech 374:305-333

Ito Y, Yamazaki S, Kurahashi T (2020) Geological features of landslides caused by the 2018 Hokkaido Eastern Iburi earthquake in Japan. Geol Soc Lond Special Publ. https://doi.org/10.1144/SP501-2019-122

Imran J, Harff P, Parker G (2001) A numerical model of submarine debris-flow with graphical user interface. Comput Geosci 27:717-729

Jeong SW, Locat J, Leroueil S, Malet JP (2010) Rheological properties of finegrained sediment: the roles of texture and mineralogy. Can Geotech J 47:1085-1100. https://doi.org/10.1139/T10-012 
Jiang L, LeBlond PH (1993) Numerical modeling of an underwater Bingham plastic mudslide and the waves which it generates. J Geophys Res 98:10303-10317

Julien PY (1995) Erosion and sedimentation. Cambridge University Press, Cambridge

Kameda J, Kamiya H, Masumoto H, Morisaki T, Hiratsuka T, Inaoi C (2019) Fluidized landslides triggered by the liquefaction of subsurface volcanic deposits during the 2018 Iburi-Tobu earthquake, Hokkaido. Sci Rep 9:13119. https://doi.org/10.1038/s41598-019-48820-y

Kawamura S, Kawajiri S, Hirose W, Watanabe T (2019) Slope failures/landslides over a wide area in the 2018 Hokkaido Eastern Iburi earthquake. Soils Found 59:2376-2395. https://doi.org/10.1016/j.sandf.2019.08.009

Kasai M, Yamada T (2019) Topographic effects on frequency-size distribution of landslides triggered by the Hokkaido Eastern Iburi earthquake in 2018. Earth Planets Space 71:89. https://doi.org/10.1186/s40623-019-1069-8

Kelfoun K, Druitt TH (2005) Numerical modeling of the emplacement of Socompa rock avalanche. Chile J Geophys Res 110:B12202. https://doi. org/10.1029/2005JB003758

Li R, Wang F (2020) Zhang S (2020) Controlling role of Ta-d pumice on the coseismic landslides triggered by 2018 Hokkaido Eastern Iburi earthquake. Landslides 17:1233-1250. https://doi.org/10.1007/ s10346-020-01349-y

Locat J (1997) Normalized rheological behavior of fine muds and their flow properties in a pseudoplastic regime. Debris-flow hazards mitigation: mechanics, prediction, and assessment. Water Resources Engineering Division, American Society of Civil Engineers, New York, pp 260-269

Malet JP, Maquaire O, Remaître A (2004) Assessing debris flow hazards associated with slow moving landslides: methodology and numerical analyses. Landslides 1:83-90

Metropolis N, Rosenbluth AW, Rosenbluth MN, Teller AH, Teller E (1953) Equation of state calculations by fast computing machines. J Chem Phys 21:1087-1092

Moretti L, Mangeney A, Walter F, Capdeville Y, Bodin T, Stutzmann E, Le Friant A (2020) Constraining landslide characteristics with Bayesian inversion of field and seismic data. Geophys J Int 221:1341-1348

Naruse H (2016) Origins of Lobate Landforms on Mars: preliminary examination from an inverse analysis of debris-flow deposits. J Geogr (chigaku Zasshi) 125:163-170
Osanai N, Yamada T, Hayashi S, Kastura S, Furuichi T, Yanai S, Murakami Y, Miyazaki T, Tanioka Y, Takiguchi S, Miyazaki M (2019) Characteristics of landslides caused by the 2018 Hokkaido Eastern Iburi earthquake. Landslides 16:1517-1528. https://doi.org/10.1007/s10346-019-01206-7

Pirulli M, Mangeney A (2008) Result of back-analysis of the propagation of rock avalanches as a function of the assumed rheology. Rock Mech Rock Eng 41:59-84

Pratson L, Imran J, Hutton E, Parker G, Syvitski JPG (2001) BANG1D: a onedimensional Lagrangian model of turbidity current mechanics. Comput Geosci 26(7):705-720

Theng BKG, Wells N (1995) The flow characteristics of halloysite suspensions. Clay Miner 30:99-106

Varnes DJ (1978) Slope movement types and processes. In: Schuster, RJ, Krizek RJ (eds) Landslides: analysis and control. Transportation Research Board, Special Report No. 176, pp 11-33

Wada K (1977) Minerals in soil environments. Soil Science Society of America, Madison, p 603

Wan Z, Wang Z (1994) Hyperconcentrated flow. IAHR monograph. Balkema, Rotterdam

Wang FR, Fan XM, Yunus AP, Subramanian SS, Alonso-Rodriguez A, Dai LX, Xu Q, Huang RQ (2019) Coseismic landslides triggered by the 2018 Hokkaido, Japan ( $\left.M_{w} 6.6\right)$, earthquake: spatial distribution, controlling factors, and possible failure mechanism. Landslide 16:1551-1566. https://doi.org/ 10.1007/s10346-019-01187-7

Yamada M, Mangeney A, Matsushi Y, Matsuzawai T (2018) Estimation of dynamic friction and movement history of large landslides. Landslides 15:1963-1974

Yamagishi H, Yamazaki F (2018) Landslides by the 2018 Hokkaido Iburi-Tobu earthquake on September 6. Landslides 15:2521-2524

Zhang S, Li R, Wang F, Lio A (2019) Characteristics of landslides triggered by the 2018 Hokkaido Eastern Iburi earthquake, northern Japan. Landslides 16:1691-1708. https://doi.org/10.1007/s10346-019-01207-6

\section{Publisher's Note}

Springer Nature remains neutral with regard to jurisdictional claims in published maps and institutional affiliations.

\section{Submit your manuscript to a SpringerOpen ${ }^{\circ}$ journal and benefit from:}

- Convenient online submission

- Rigorous peer review

- Open access: articles freely available online

- High visibility within the field

- Retaining the copyright to your article

Submit your next manuscript at $\boldsymbol{\nabla}$ springeropen.com 